\title{
Cyclophosphamide Depletes Ovarian Follicles in Mice During Both the Light and Dark Phases of the Circadian Cycle
}

\author{
Benjamin Z. Koch \& Kristen A. Roosa* \\ Biology Department, State University of New York College at Oneonta, Oneonta, NY \\ bttps://doi.org/10.33697/ajur.2020.023 \\ Student:bkoch4@jh.edu \\ Mentor: Kristen.roosa@oneonta.edu*
}

\begin{abstract}
The alkylating agent cyclophosphamide (CY) is a potent ovarian toxicant. It damages growing follicles and causes premature activation and depletion of the resting follicles that constitute the ovarian reserve. While there is abundant information on the impact of CY on the ovary and its toxicity mechanisms, the influence of the circadian rhythm on ovarian toxicity has not been evaluated. To test the hypothesis that time of exposure affects ovarian toxicity of CY, C57BL/6 mice were treated with a single injection of CY $(75 \mathrm{mg} / \mathrm{kg}$ ) at either two hours after lights on (Zeitgeber time (ZT) 02) or two hours after lights off (ZT14). Toxicity was evaluated one week after treatment by counting ovarian follicles in histological sections. Fewer primordial follicles were counted in the ovaries of $\mathrm{CY}$-treated animals at both treatment times, and fewer antral follicles were counted in the ovaries of animals treated at ZT02. There was no difference in the number of primordial follicles in the ovaries of CY-treated animals between the two treatment times. These results demonstrate that CY-induced depletion of the ovarian reserve occurs when mice are exposed early in the light phase and early in the circadian cycle's dark phase. There is no impact of the circadian rhythm on follicle depletion by CY at these time points.
\end{abstract}

\section{KEYWORDS}

Cyclophosphamide; ovary; circadian; ovarian follicles; toxicity; mouse; chronotherapy; alkylating agent

\section{INTRODUCTION}

Female mammals are endowed with a finite number of germ cells (i.e., oocytes) assembled in follicles composed of somatic cells. Non-growing primordial follicles represent a female's ovarian reserve. ${ }^{1,2}$ In healthy females, the number and quality of ovarian follicles decrease gradually throughout life. ${ }^{3}$ Eventually, a high degree of germ cell depletion contributes to ageassociated reproductive senescence and infertility. ${ }^{4,5}$ The age-associated decline in the oocyte reserve may be accelerated by exposure to environmental toxicants that damage ovarian follicles. ${ }^{6-9}$

Many routinely used chemotherapeutic agents are toxic to the ovary. They are a significant source of ovarian toxicant exposure in pre-menopausal women. ${ }^{8}, 10$ Alkylating agents are particularly harmful to the ovary. These compounds add alkyl groups to DNA, interfering with transcription, DNA replication, and cell division. ${ }^{11}$ Alkylating agent exposure is associated with a significantly reduced ovarian follicle reserve, ${ }^{12,13}$ amenorrhea, ${ }^{14}$ and premature ovarian insufficiency in women. ${ }^{15}, 16$

Cyclophosphamide (CY) is a bifunctional alkylating agent that induces DNA crosslinks and double-strand breaks. ${ }^{11} \mathrm{It}$ is the cornerstone of chemotherapy regimens used to treat cancers in women, such as breast cancer, ovarian cancer, and nonHodgkin lymphoma. ${ }^{17}$ It is also used to treat autoimmune disorders such as systemic lupus erythematosus, ${ }^{18}$ which predominantly affect females. ${ }^{19}$

Cyclophosphamide is a potent ovarian toxicant. Exposure is associated with reduced primordial follicle reserve ${ }^{20}$ and an increased risk of acute ovarian failure in women treated as young adults. ${ }^{14,15}$ In rodents, a single dose $(75 \mathrm{mg} / \mathrm{kg})$ is sufficient to reduce the primordial follicle reserve by $50 \% .^{21,22}$ Cyclophosphamide significantly reduced the number of primordial follicles in human ovarian tissue mouse xenograft experiments. ${ }^{23}, 24$ Treatment of human ovarian xenografts was also associated with increased follicular apoptosis as measured by TUNEL staining ${ }^{24}$ and cleaved caspase-3 quantification. ${ }^{23}$

As cancer survival rates continue to improve, and women delay childbearing to later in life, preserving females' fertility exposed to ovarian toxicants such as $\mathrm{CY}$ has become an important research area. ${ }^{25}$ Current strategies for fertility preservation during chemotherapy include cryopreservation of ovarian tissue, germ cells, or embryos. ${ }^{26}$ Researchers continue to search for less invasive methods to spare females' fertility after exposure to alkylating agents.

The science of chronotherapy involves treating illnesses according to a patient's biological rhythms. The goals of chronotherapy are to minimize toxicity and enhance the effectiveness of pharmaceutical agents. ${ }^{27}$ Twenty-four-hour circadian rhythms in drug response have been observed for many compounds, including at least 40 anticancer agents and ten alkylating 
agents. ${ }^{28}$ Therefore, biological rhythms may be an important consideration during chemotherapy when pre-menopausal women are exposed to alkylating agents.

There is specific evidence that the degree of CY toxicity is influenced by the time of exposure. Male mice treated with CY (3 doses of $150 \mathrm{mg} / \mathrm{kg}$ ) at the light to dark transition of their daily cycle (Zeitgeber time (ZT)14) had better survival (80\%) and retained more bodyweight after CY than those treated at the dark to light transition (ZT02, 20\% ${ }^{29}$. Others had reported the most significant survival rate in mice when they were treated with a single dose of CY $(375 \mathrm{mg} / \mathrm{kg})$ in the four hours around the light to dark transition compared to other times of the day. ${ }^{30}$

While there is abundant information available on the effects of CY on the ovary and its toxicity mechanisms, the influence of the circadian rhythm on its ovarian toxicity has not been evaluated. This study aimed to determine if a circadian rhythm in CY toxicity is evident at a sub-lethal dose that induces significant follicle depletion. A rhythm in ovarian toxicity could be important for CY treatment in women when ovarian follicles should be spared. Furthermore, the circadian rhythm may be an important variable to consider as studies on other ovarian toxicants are planned and reported. We predicted that CY would deplete the ovarian reserve when mice were exposed at both ZT02 and ZT14, but that toxicity would be less severe in the group treated at ZT14. To test this hypothesis, mice were treated with a single dose of CY $(75 \mathrm{mg} / \mathrm{kg})$ at times predicted to yield the most (ZT02) and least (ZT14) overall toxicity. ${ }^{29}$ Ovarian follicles were classified and counted in histological sections one week after treatment.

\section{METHODS AND PROCEDURES}

Animals

Breeding pairs of C57BL/ 6 mice were obtained from the Jackson Laboratory to generate experimental females for this study. Experimental females were weaned at 21 days old and individually housed in polycarbonate cages with aspen shaving bedding. The light cycle was the main time indicator (Zeitgeber) for the mice in this experiment. All animals were held on a 12-hour light/12-hour dark cycle. The time of lights on was Zeitgeber time 00 (7:00 am EST). Animals were provided with water and chow (Mazuri Rat and Mouse Diet) ad libitum. The temperature was $20 \pm 2{ }^{\circ} \mathrm{C}$ and humidity $30 \pm 10 \%$. All animal procedures were approved by the Institutional Animal Care and Use Committee at the State University of New York at Oneonta (protocol 2016-20).

Treatments

At six weeks old, each female was assigned to one of four treatment groups (seven to eight animals per group). The CYtreated females received an intraperitoneal injection of CY $(75 \mathrm{mg} / \mathrm{kg}$ in saline, Sigma Aldrich) at either ZT02 or ZT14. Control animals received an injection of saline at an equivalent volume at ZT02 or ZT14. All animals were killed at ZT12 by $\mathrm{CO}_{2}$ inhalation one week following the injection. The final body mass of each animal was recorded. The ovaries were removed, dissected free of fat and connective tissue, and weighed. The left ovary was used for histological analysis.

Tissue preparation and histological evaluation

The left ovary from each animal was fixed in 10\% buffered formalin overnight and then serially dehydrated in ethanol. Ovaries were embedded in paraffin and serially sectioned at five $\mu \mathrm{m}$. Every tenth section was placed on a glass slide and stained with hematoxylin and eosin. Sections were viewed under 400X magnification, and ovarian follicles were classified and counted. Oocytes surrounded by a single layer of flattened granulosa cells were classified as primordial. Primary follicles were characterized by an oocyte surrounded by a single layer of cuboidal granulosa cells. The oocytes of secondary follicles were surrounded by more than one layer of cuboidal granulosa cells, and antral follicles were characterized by having multiple layers of cuboidal granulosa cells and an antral space. ${ }^{31}$ Follicles were classified as atretic if the following were observed: degenerating oocyte and/or $>10 \%$ granulosa cells containing apoptotic bodies. ${ }^{32}$ Only follicles containing oocytes with a visible nucleus were counted.

\section{Statistical analysis}

Data were analyzed with JMP version 14.0.0 (SAS Institute, Inc.). A generalized linear model with planned comparisons was used to compare the numbers of follicles (primordial, primary, and secondary, antral, atretic, and total) counted in the ovaries of each CY treated group to controls and among the two treatment times. Levene's test was used to test for equal variance in follicle numbers between females treated at ZT02 and ZT14. All results were expressed as mean \pm standard error of the mean (SEM). The level of significance $(\alpha)$ for each test was 0.05 .

\section{RESULTS}

Representative histological sections from each treatment group are shown in Figure 1. A single dose of cyclophosphamide $(75 \mathrm{mg} / \mathrm{kg}$ ) significantly reduced the number of primordial follicles counted in the ovaries of mice treated both at two hours after lights on (ZT02, 37\% reduction) and two hours after lights off (ZT14, 39\% reduction, Figure 2). However, there was no difference in the number of primordial follicles in the ovaries of females treated at ZT02 and ZT14 (p = 0.64), indicating that time of treatment did not affect this measure of ovarian toxicity. In addition to depleting primordial follicles, 
cyclophosphamide reduced the number of antral follicles in the ovaries of mice treated at ZT02. This was not observed in females treated at ZT14, and animals treated at ZT14 had significantly more antral follicles than those treated at ZT02.
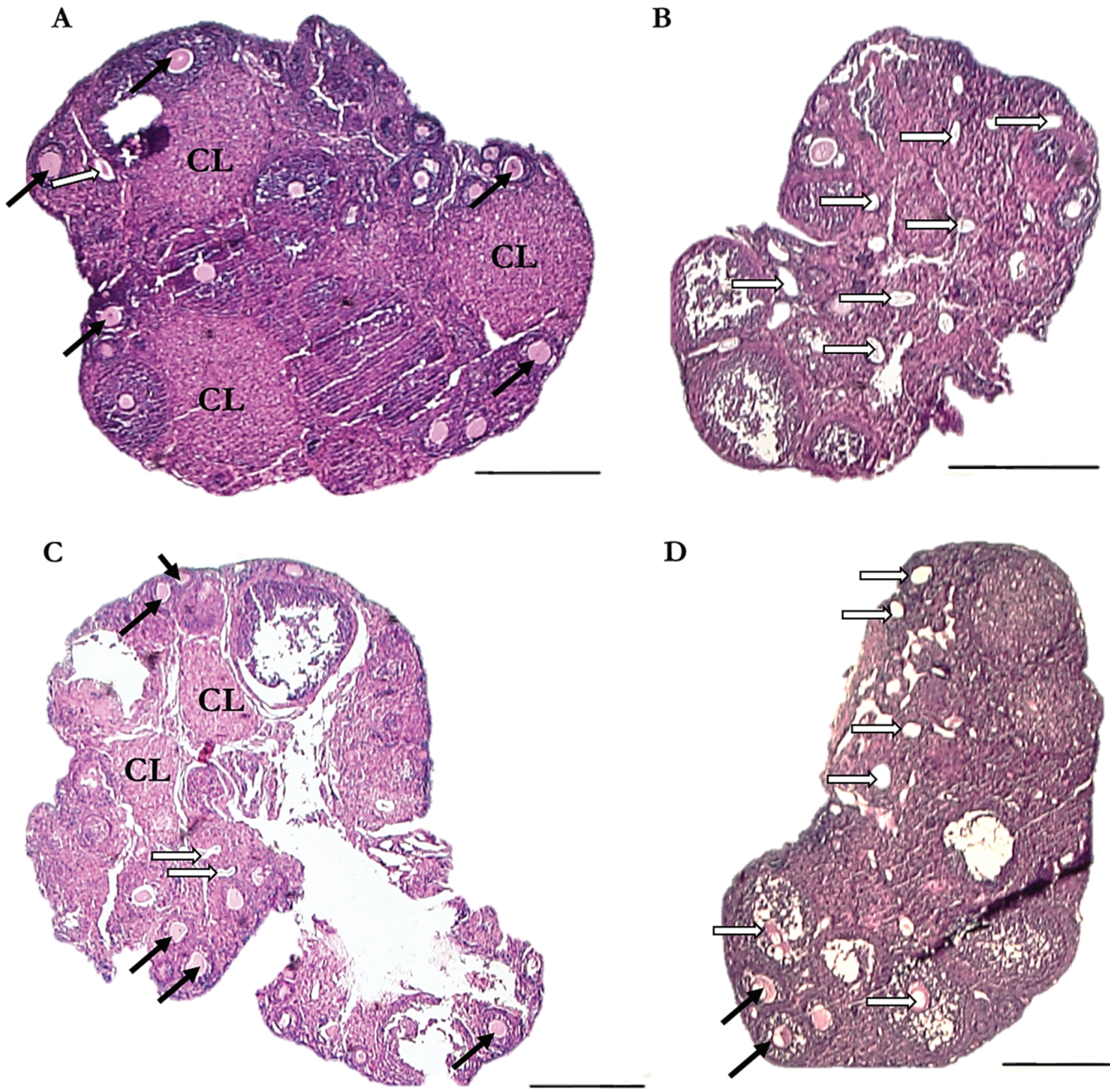

D

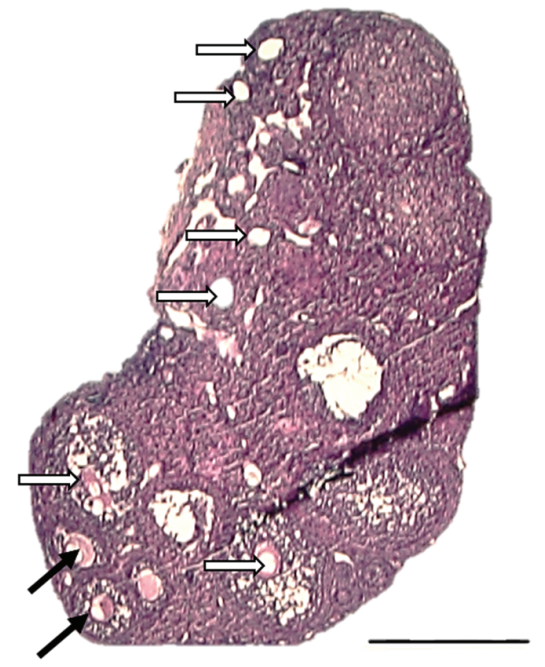

Figure 1. Representative photomicrographs (40X magnification) of ovaries from six-week-old mice treated with saline vehicle at ZT02 (A) or ZT14 (C) or CY at ZT02 (B) or ZT14 (D). Solid arrows indicate healthy secondary follicles, and open arrows indicate remnants of atretic follicles. CL indicates corpora lutea. Scale bars $=500 \mu \mathrm{m}$.

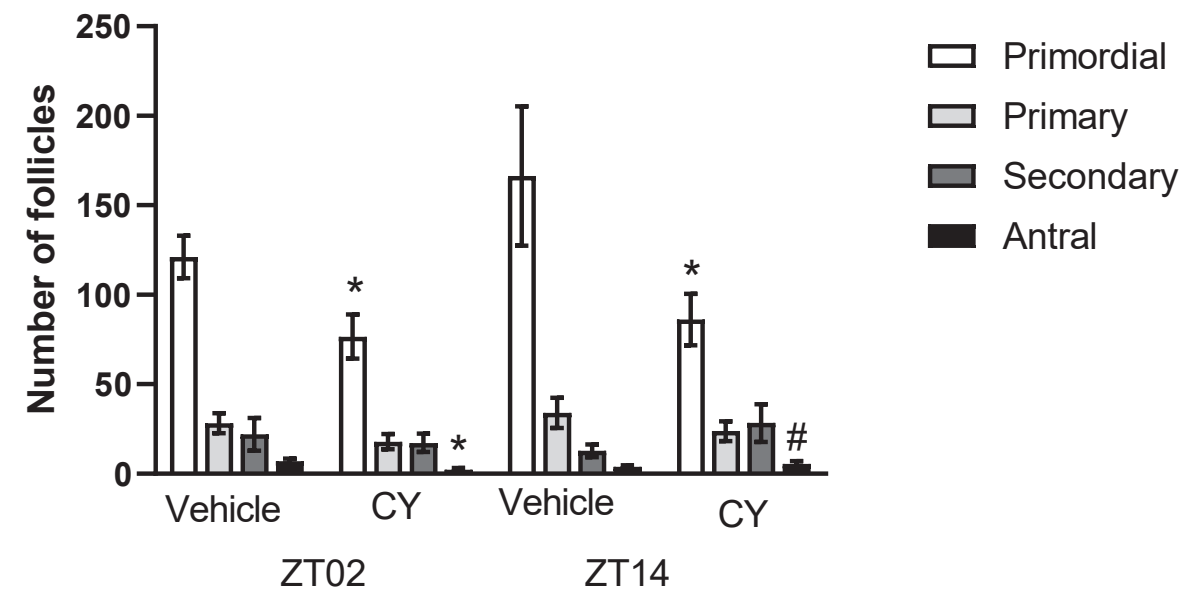

Figure 2. Mean $\left( \pm\right.$ SEM) number of follicles counted in every $10^{\text {th }}$ section of one ovary from six-week-old mice treated with $C Y$ or vehicle at ZT02 and ZT14. * indicates a significant difference $(\mathrm{p}<0.05)$ between CY and vehicle-treated animals within the same treatment time, and \# indicates a significant difference between CY-treated animals between ZT02 and ZT14 $(\mathrm{p}=0.034)$. Sample sizes were 4-8 females per group. 
The total number of follicles counted was also compared among the groups. There was a trend toward a decreased total number of follicles counted in the CY group treated at ZT02 as compared to the time-matched controls ( $\mathrm{p}=0.075$, Figure 3). There was no significant decrease in the number of follicles counted when mice were treated at ZT14 ( $p=0.22)$, and there was no significant difference between treatment times $(\mathrm{p}=0.36)$. Atretic follicles were counted, and there were no differences in the number across any of the comparisons made.

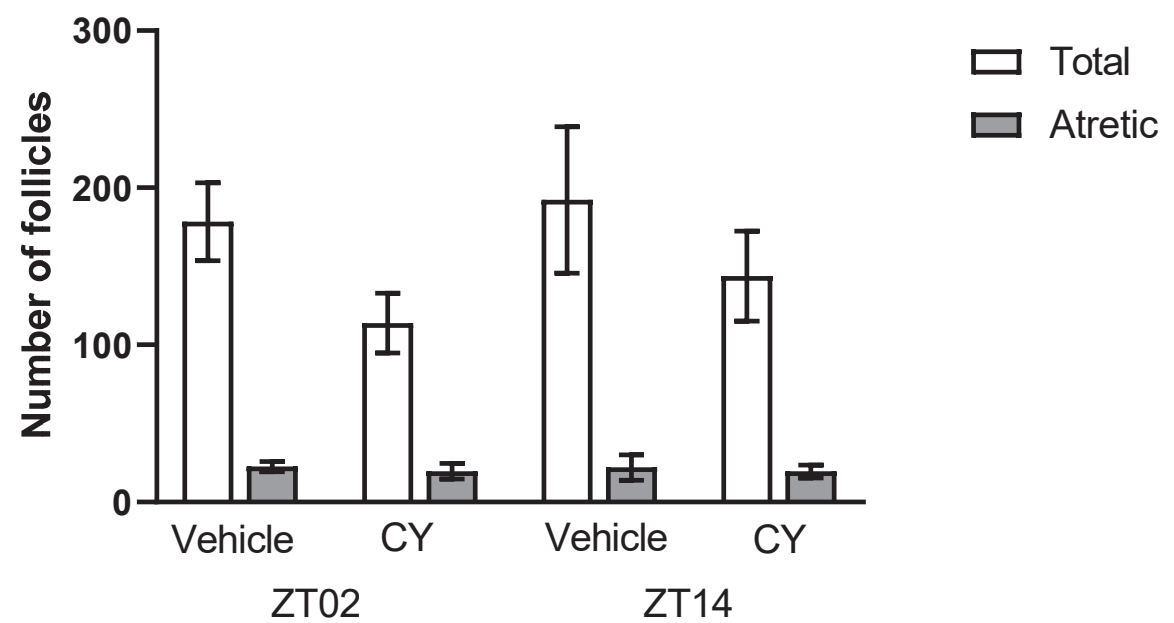

Figure 3. Mean ( \pm SEM) number of follicles of all stages of development combined and atretic follicles counted in every $10^{\text {th }}$ section of one ovary of sixweek-old mice treated with CY or vehicle at ZT02 and ZT14. Sample sizes were 4-8 females per group.

\section{DISCUSSION}

Significant depletion of primordial follicles after CY treatment was expected, based on the results of previous studies using this dose ${ }^{21-33}$. We predicted that females treated at ZT14 would have a greater resistance to CY than those treated at ZT02 (i.e., more primordial follicles remaining after treatment). This prediction was based on the reduced mortality in mice after high-dose CY treatment at ZT14 as compared to ZT02.29, 30 The data did not support our hypothesis and suggest that CY reduces the pool of ovarian follicles when animals are exposed both in the light and dark phases of the circadian cycle.

Cyclophosphamide induces premature activation of dormant primordial follicles, which accelerates the depletion of the follicle reserve. ${ }^{33}$ It also induces apoptosis in both dormant and growing follicles. ${ }^{23,} 24,34$ In previous studies, there was at least a $50 \%$ reduction in primordial follicles in mice seven days after a single dose of $75 \mathrm{mg} / \mathrm{kg}$ CY. ${ }^{21,33}$ The degree of follicle depletion by CY in our study is more consistent with the results of Plowchalk \& Mattison, ${ }^{9}$ where there was about a $33 \%$ reduction in primordial follicles.

Others have reported a reduction of antral follicles after CY treatment with either a higher dose $\left(200 \mathrm{mg} / \mathrm{kg}^{9}\right)$ or $\mathrm{more}$ acutely after treatment ( 3 days following an injection of $75 \mathrm{mg} / \mathrm{kg}^{22}$ ). Given that the resting follicle reserve is considered the most representative indicator of long-term ovarian health and fertility, their number is likely more biologically meaningful than the number of antral follicles.

While the atretic follicle number has increased after CY treatment in rodents, it was observed either after in vitro exposure or when ovaries were observed 24 hours after treatment. ${ }^{34,35}$ There were no signs of systemic toxicity after treatment with cyclophosphamide at either time. The change in body mass throughout the treatment or ovary mass did not differ from controls or between CY treatment groups (data not shown).

Dosage is likely a major reason for the presence of a circadian rhythm in CY toxicity when mortality is the endpoint but not for ovarian toxicity. We used a dose that results in depletion of follicles but not systemic toxicity. This dosage (a single injection of $75-100 \mathrm{mg} / \mathrm{kg}^{21,22}$ ) is low compared to the lethal doses used in previous studies (3 doses of $150 \mathrm{mg} / \mathrm{kg}$ ) that demonstrated an impact of the circadian rhythm on toxicity and mortality. Additionally, ovarian toxicity and depletion of follicles require a single injection of $\mathrm{CY}$, whereas circadian effects of toxicity were observed after repeated doses $(3 \times 150$ $\mathrm{mg} / \mathrm{kg}$ ). While multiple doses may better mimic what women undergoing cancer treatment are exposed to, this is difficult to recapitulate due to the great amount of variability in chemotherapy regimens. Whether the circadian rhythm impacts ovarian toxicity after multiple doses of CY remains unknown.

We focused on follicle depletion as the toxicity outcome after CY treatment. This is commonly used as a measure of CY toxicity by many investigators in mechanistic studies and investigations of potential ameliorators of ovarian damage. ${ }^{22,23,33,36,}$ 
${ }^{37}$ It is unlikely that the dose we administered would significantly impact fertility one week after treatment, ${ }^{21}$ therefore, it was not tested. However, it remains unknown if the circadian rhythm would impact fertility after CY treatment in the long term or in aged animals with an already diminished primordial follicle reserve.

Given current information on circadian patterns in toxicity in rodents, it seems unlikely that other points in the circadian cycle would yield different results in ovarian toxicity. We evaluated time points based on the maximum and minimum times of sensitivity for a high dose of cyclophosphamide $(300-375 \mathrm{mg} / \mathrm{kg}){ }^{29},{ }^{30} \mathrm{In}$ rodents, significant differences in sensitivity to several other toxicants have been observed when animals were exposed just after lights on and just after lights off, ${ }^{38-40}$ including the toxicity of the alkylating agent cisplatin. ${ }^{40}$ Given these trends, it is unlikely that other times in the circadian cycle would impact ovarian toxicity of CY (e.g., middle of dark or light phases).

\section{CONCLUSIONS}

To our knowledge, this is the first evaluation of the potential impact of the circadian rhythm on ovarian toxicity. We report that time of treatment does not impact the toxicity of CY, in terms of follicle depletion, at two specific times in the circadian rhythm. Future studies to evaluate the influence of time of treatment with longer-duration dosing regimens or in combination with other alkylating chemotherapeutic agents may shed more light on the role the circadian rhythm may play in ovarian toxicity of CY.

\section{ACKNOWLEDGEMENTS}

This research was funded by the Research Foundation for the State University of New York. The authors thank Morgan Gray, Brittany Riddick, and Coreena Monroe for their technical assistance and Dr. Jennifer Nagashima for her review of this manuscript. We also thank the anonymous reviewers for their constructive feedback on an earlier draft of this article.

\section{REFERENCES}

1. Gougeon A. (2004) Dynamics of human follicular growth: morphologic, dynamic, and functional aspects, in The Ovary (Leung, P. \& Adashi E., Eds.) 2nd ed., 25-38. Elsevier Academic Press, San Diego, CA.

2. Kerr, J. B., Myers, M., and Anderson, R. A. (2013) The dynamics of the primordial follicle reserve, Reproduction 146(6), R205-R215. bttps:// doi.org/10.1530/ rep-13-0181

3. Faddy, M.J. (2000) Follicle dynamics during ovarian ageing, Mol Cell Endocrinol 163, 43-48. https://doi.org/10.1016/s03037207(99)00238-5

4. Gosden, R. G., Laing, S. C., Felicio, L. S., Nelson, J. F., and Finch, C. E. (1983) Imminent oocyte exhaustion and reduced follicular recruitment mark the transition to acyclicity in aging C57Bl/6J mice, Biol Reprod 28(2), 255-260. bttps:// doi.org/ 10.1095/ biolreprod28.2.255

5. Nelson, J. F., Felicio, L. S., Randall, P. K., Sims, C., and Finch, C.E. (1982) A longitudinal study of estrous cyclicity in aging c57bl-6j mice: cycle frequency, length and vaginal cytology, Biol Reprod 27(2), 327-339. bttps:/ / doi.org/10.1095/ biolreprod27.2.327

6. Dyer, C.A., Raymond-Whish, S., Schmuki, S., Fisher, T., Pyzyna, B., Bennett, A., and Mayer, L. P. (2013) Accelerated follicle depletion in vitro and in vivo in Sprague-Dawley rats using the combination of 4-vinylcyclohexene diepoxide and triptolide, J Zoo Wildl Med 44(4 Suppl), S9-17. https:/ / doi.org/ 10.1638/1042-7260-44.4s.s9

7. Igawa, Y., Keating, A. F., Rajapaksa, K. S., Sipes, I. G., and Hoyer, P. B. (2009) Evaluation of ovotoxicity induced by 7 , 12-dimethylbenz[a]anthracene and its 3,4-diol metabolite utilizing a rat in vitro ovarian culture system. Toxicol Appl Pharmacol, 234(3), 361-369. bttps:// doi.org/10.1016/j.taap.2008.10.009

8. Meirow, D., and Nugent, D. (2001) The effects of radiotherapy and chemotherapy on female reproduction. Hum Reprod Update, 7(6), 535-543. bttps:// doi.org/10.1093/ humupd/7.6.535

9. Plowchalk, D. R., and Mattison, D. R. (1992) Reproductive toxicity of cyclophosphamide in the C57BL/6N mouse: 1. Effects on ovarian structure and function, Reprod Toxicol, 6(5), 411-421. https:// doi.org/10.1016/0890-6238(92)90004-d

10. Mark-Kappeler, C. J., Hoyer, P. B., and Devine, P. J. (2011) Xenobiotic effects on ovarian preantral follicles, Biol Reprod 85(5), 871-883. bttps:/ / doi.org/10.1095/ biolreprod.111.091173

11. Fu, D., Calvo, J. A, and Samson, L. D. (2012) Balancing repair and tolerance of DNA damage caused by alkylating agents, Nat Rev Cancer 12(2), 104-120. https:// doi.org/10.1038/nrc3185

12. Gracia, C. R., Sammel, M. D., Freeman, E., Prewitt, M., Carlson, C., Ray A., Vance, A., and Ginsberg, J. P (2012) assessing the impact of cancer therapies on ovarian reserve, Fertil Steril 97(1), 134-140. https:// dx.doi.org/10.1016\%2Fj.fertnstert.2011.10.040

13. Oktem, O., and Oktay, K. (2007) Quantitative assessment of the impact of chemotherapy on ovarian follicle reserve and stromal function, Cancer 110(10), 2222-2229. https:/ / doi.org/10.1002/ cncr.23071

14. Minton, S. E., and Munster, P. N. (2002) Chemotherapy-induced amenorrhea and fertility in women undergoing adjuvant treatment for breast cancer, Cancer Control 9(6), 466-472. https:// doi.org/10.1177/107327480200900603

15. Chemaitilly, W., Mertens, A. C, Mitby, P., Whitton, J., Stovall, M., Yutaka, Y., Robinson, L. L., and Sklar, C. A. (2006) Acute ovarian failure in the childhood cancer survivor study, J Clin Endocrinol Metab 91(5), 1723-1728.

bttps:/ / doi.org/10.1210/jc.2006-0020 
16. Chemaitilly, W., Li, Z., Krasin, M. J., Brooke, R. J., Wilson, C. L., Green, D. M., Klosky, J. L., Barnes, N., Clark K. L., Farr, J. B., Fernandez-Pineda, I., Bishop, M. W., Metzger, M., Pui, C., Kaste, S. C., Ness, K. K., Srivastava, D. K., Robison, L. L., Hudson, M. M., Yasui, Y. and Sklar, C. A. (2017) Premature ovarian insufficiency in childhood cancer survivors: A report from the St. Jude Lifetime Cohort, J Clin Endocrinol Metab 102(7), 2242-2250. bttps:/ / doi.org/ 10.1210/jc.2016-3723

17. Emadi, A., Jones, R. J., and Brodsky, R. A. (2009) Cyclophosphamide and cancer: golden anniversary, Nat Rev Clin Oncol 6(11), 638-647. https://doi.org/10.1038/nrclinonc.2009.146

18. Lisnevskaia, L., Murphy, G., and Isenberg, D. (2014) Systemic lupus erythematosus, Lancet, 384(9957), $1878-1888$. https:/ / doi.org/10.1016/S0140-6736(14)60128-8

19. Cooper, G. S., and Stroehla, B. C. (2003) The epidemiology of autoimmune diseases, Autoimmun Rev 2(3), $119-125$. bttps:// doi.org/10.1016/s1568-9972(03)00006-5

20. Marcello, M. F., Nuciforo, G., Romeo, R., Di Dino, G., Russo, I., Russo, A., Palumbo, G., and Schiliro, G. (1990) Structural and ultrastructural study of the ovary in childhood leukemia after successful treatment, Cancer 66(10), 20992104. bttps:/ / doi.org/ 10.1002/1097-0142(19901115)66:10\%3C2099::AID-CNCR2820661010\%3E3.0.CO;2-3

21. Meirow, D., Lewis, H., Nugent, D., and Epstein, M. (1999) Subclinical depletion of primordial follicular reserve in mice treated with cyclophosphamide: clinical importance and proposed accurate investigative tool, Hum Reprod 14(7), 19031907. https:// doi.org/10.1093/ bumrep/14.7.1903

22. Plowchalk, D. R., and Mattison, D. R. (1991) Phosphoramide mustard is responsible for the ovarian toxicity of cyclophosphamide, Toxicol Appl Pharmacol 107(3),472-481. https:// doi.org/10.1016/0041-008x(91)90310-b

23. Li, F., Turan, V., Lierman, S., Cuvelier, C., De Sutter, P., and Oktay, K. (2014) Sphingosine-1-phosphate prevents chemotherapy-induced human primordial follicle death, Hum Reprod 29(1), 107-113. bttps://doi.org/10.1093/ bumrep/det391

24. Oktem, O., and Oktay, K. (2007) A novel ovarian xenografting model to characterize the impact of chemotherapy agents on human primordial follicle reserve, Cancer Res 67(21), 10159-10162. https:/ / doi.org/10.1158/0008-5472.can-07-2042

25. Roness, H., Kashi, O., and Meirow, D. (2016) Prevention of chemotherapy-induced ovarian damage, Fertil Steril 105(1), 20-29. https:// doi.org/10.1016/j.fertnstert.2015.11.043

26. Kim, S. Y., Kim, S. K,. Lee, J. R., and Woodruff, T. K. (2016) Toward precision medicine for preserving fertility in cancer patients: existing and emerging fertility preservation options for women, J Gynecol Oncol 27(2), e22 bttps://doi.org/10.3802/jgo.2016.27.e22

27. Ballesta, A., Innominato, P., Dallmann, R., Rand, D., and Levi, F. (2017) Systems chrontherapeutics, Pharmacol Rev 69(2), 161-199. https:// doi.org/10.1124/pr.116.013441

28. Lévi, F., Okyar. A., Dulong, S., Innominato, P. F., and Clairambault, J. (2010) Circadian timing in cancer treatments, Anпu Rev Pharmacol Toxicol 50, 377-421. https:// doi.org/10.1146/annurev.pharmtox.48.113006.094626

29. Gorbacheva, V. Y., Kondratov, R. V., Zhang, R., Cherukuri, S., Gudkov, A. V., Takahashi, J. S, and Antoch, M. P. (2005) Circadian sensitivity to the chemotherapeutic agent cyclophosphamide depends on the functional status of the CLOCK/BMAL1 transactivation complex, Proc Natl Acad Sci USA., 102(9), 3407-3412. https:// doi.org/10.1073/pnas.0409897102

30. Haus, E., Fernandes, G., Kühl, J. F., Yunis, E. J. , Lee, J. K., and Halberg, F. (1974) Murine circadian susceptibility rhythm to cyclophosphamide, Chronobiologia 1(3), 270-277.

31. Place, N. J., and Cruickshank, J. (2009) Graded response to short photoperiod during development and early adulthood in Siberian hamsters and the effects on reproduction as females age, Horm Behav 55(3), 390-397. bttps:// doi.org/10.1016/j.ybbeh.2009.01.005

32. Greenfield, C., Babus, J., Furth, P., Marion, S., Hoyer, P., and Flaws, J. (2007) BAX is involved in regulating follicular growth, but is dispensable for follicle atresia in adult mouse ovaries, Reproduction 133(1), 107-116. https:/ / doi.org/ 10.1530/ rep-06-0144

33. Kalich-Philosoph L, Roness H, Carmely A, Fishel-Bartal, M., Ligumsky, H., Paglin, S., Wolf, I., Kanety, H., Sredni, B., and Meirow, D. (2013) Cyclophosphamide triggers follicle activation and "burnout"; AS101 prevents follicle loss and preserves fertility, Sci Transl Med. 5(185), 185ra162. https:// doi.org/10.1126/ scitranslmed.3005402

34. Desmeules, P., and Devine, P.J. (2006) Characterizing the ovotoxicity of cyclophosphamide metabolites on cultured mouse ovaries, Toxicol Sci 90(2), 500-509. https:/ / doi.org/10.1093/toxsci/ kefj086

35. Lopez, S.G, and Luderer, U. (2004) Effects of cyclophosphamide and buthionine sulfoximine on ovarian glutathione and apoptosis, Free Radic Biol Med 36(11), 1366-1377. https:/ / doi.org/10.1016/j.freeradbiomed.2004.02.067

36. Meirow, D, Assad, G., Dor, J., and Rabinovici J. (2004) The GnRH antagonist cetrorelix reduces cyclophosphamideinduced ovarian follicular destruction in mice, Hum Reprod 19(6),1294-1299. https:// doi.org/10.1093/ humrep/deh257

37. Madden, J. A., Hoyer, P. B, Devine, P. J, and Keating, A. F. (2014) Involvement of a volatile metabolite during phosphoramide mustard-induced ovotoxicity, Toxicol Appl Pharmacol 277(1),1-7. bttps:// doi.org/10.1016/j.taap.2014.03.006

38. DeBruyne, J. P, Weaver, D. R, and Dallmann, R. (2014) The hepatic circadian clock modulates xenobiotic metabolism in mice, J Biol Rhythms 29(4), 277-287. https:/ / doi.org/10.1177/0748730414544740

39. Johnson, B. P., Walisser, J. A., Liu, Y., Shen, A. L., McDearmon, E. L., Moran, S. L., McIntosh, B. E., Vollrath, A. L., Schook, A. C., Takahashi, J. S., and Bradfield, C. A. (2014) Hepatocyte circadian clock controls acetaminophen bioactivation through NADPH-cytochrome P450 oxidoreductase, Proc Natl Acad Sci USA. 111(52), 18757-18762. https:// doi.org/10.1073/pnas.1421708111 
40. Dakup, P. P., Porter, K. I., Little, A. A., Gajula, R. P., Zhang, H., Skornyakov, E., Kemp, M. G., Van Dongen, H. P. A., and Gaddameedhi, S. (2018) The circadian clock regulates cisplatin-induced toxicity and tumor regression in melanoma mouse and human models, Oncotarget 9(18), 14524-14538. https:// doi.org/ 10.18632/ oncotarget.24539

\section{ABOUT STUDENT AUTHOR}

Benjamin Koch recently graduated from SUNY Oneonta with a B.S. with a focus in biology and organic chemistry. Benjamin's interest in preserving the health of the environment for the enjoyment and use of future generations was inspired by his time spent researching, and SCUBA diving in, the freshwater lakes and stream surrounding Oneonta and Cooperstown. He is currently working towards his Master's Degree in Environmental Science and Policy at John Hopkins University. He plans to one day be able to enact meaningful environmental solutions that will help mitigate the current effects of global climate change on natural resources.

\section{PRESS SUMMARY}

Many of the chemicals used to treat cancer patients also have negative side effects, including damaging the ovary. cyclophosphamide $(\mathrm{CY})$ is one such chemical commonly used during chemotherapy. CY is a known alkylating agent that interferes with DNA replication cell division. This is useful for fighting cancer cells, but it also damages egg cells (oocytes). Finding ways to mitigate the harmful effects of these ovarian toxicants was a primary focus of this study. One theory that was tested involved giving female mice sub-lethal dosages of the CY at two different stages of their circadian rhythm (in the evening vs. the morning). We hypothesized that the mice who receive the treatment when they are most metabolically active (in the evening) would have a higher resistance to the toxicant. These mice would be presumed to have more viable ovarian follicles left intact after the treatment. While previous studies have shown that chronotherapy is a viable method in reducing mice mortality to a lethal dosage of $\mathrm{CY}$, no prior research has shown how the resistance of ovarian follicle health to toxins can be linked to metabolic rate. Our results suggest that the circadian rhythm has no significant effect on the mice's ovarian resistance to $\mathrm{CY}$ at times tested. 